\title{
A Survey of Methods for Achieving Efficiency in Electricity Consumption
}

\author{
P. Ozoh \\ Department of information \\ and communication technology \\ Osun State University, Nigeria
}

\author{
S. Abd-Rahman \\ Faculty of computer science \\ and information technology \\ Universiti Malaysia, Sarawak
}

\author{
J. Labadin \\ Faculty of computer science \\ and information technology \\ Universiti Malaysia, Sarawak
}

\begin{abstract}
This paper investigates related research work on electricity consumption in buildings and outlines its context relative to improving efficiency in appliance usage by customers. The aim of this research is to study the impact of applying powersaving measures on appliance usage in order to reduce electric costs. The study focuses on a review of tools and methods involved in achieving efficient electricity consumption system with respect to minimization of electric costs and reduction of electricity wastage in the system. It also conducts a survey of various literatures involving the potential impact of incorporating power-saving measures on low-power and highpower appliances to allow for more efficient use of electrical appliances. The paper provides a number of recommendations for achieving efficiency in electricity consumption, when power-saving measures are applied to appliance usage.
\end{abstract}

\section{Keywords}

Efficiency, power-saving measures, electricity wastage, lowpower appliances, high-power appliances

\section{INTRODUCTION}

The growing global demand for energy is making it imperative that newer and more efficient electricity appliance use is deployed. Energy efficiency is also an important issue because of the constantly changing electricity consumption pattern across the globe. These are the most important driving factors resulting in the development and implementation of different energy efficiency systems. On the basis of secondary research, the emerging trends in energy research have been identified in this study, thus providing an insight in electricity consumption efficiency. The study also provides a comprehensive description of the challenges faced by this market. The research study involves the usage of extensive primary and secondary sources: electricity consumption collected for individual appliances over a period of time, research papers, industry white papers, case studies, presentations, and other publicly available sources, to identify and collect information useful for building this extensive database for efficiency in electricity consumption. There is a need to use electric appliances in a more efficient manner so as to reduce costs. This is more so as the global energy consumption has increased due to an increase in population, production, and industrialization (International Energy Agency, 2013). Due to the importance of having an efficient power management system, past studies have focused on the efficient utilization of electric appliances in households and industrial energy consumption. A study by Lee, Kim, \& Park (2012) showed electricity consumers recognized and realized that efficiency in consumption is an important attribute in power usage and management and it is also an important differentiator between electric power distribution and consumption.

A research paper by Fontana, Atella, \& Kammen (2013) provided a strong analogy between energy consumption in buildings and industrial growth, in terms of human, environmental, and health. The research paper suggested that achieving energy efficiency will greatly have a profound transformation effect on industrial and economic development, hence impacting on reducing energy costs. These factors will significantly increase the health span; reduce health costs, environmental pollution, production and global warming. As a result of findings from this paper, houses were made more energy efficient. For example, installation of wall and roof insulation, energy-efficient windows and doors, ultra-efficient lighting technologies, energy-saving appliances, solar power to heat water and produce electricity, geothermal heat pumps, etc. led to more efficient use of electricity. Achieving energy efficiency and resource productivity paradigm offers a new ground for business invention, sustainable growth and economic development. Kiely et al. (2010) proposed the dependence on energy-efficiency utilities as a key to stimulate faltering economies during economic downturns. (Auffhammer \& Aroonruengsawat, 2012) investigated the impact of higher temperatures on global residential electricity consumption for different climatic zones. The paper suggested that electricity consumption will vary according to temperature response across different climatic zones, which allows for differential effects of days with different mean temperatures on households' electricity consumption. Section 2 discusses the impact of applying power-saving measures on appliance usage. Section 3 discusses literature on activity profile measurements for appliance usage. In Section 4, models of domestic load for appliances used in this study are described. Conclusions are drawn in Section 5.

\section{EFFICIENCY IN APPLIANCE USAGE}

In essence, electricity efficiency and introducing control mechanisms to electricity consumption plays important roles in minimizing electricity wastages and reducing the cost of electricity. Applying control techniques to electric appliances would improve efficiency in the use of electricity. However, the lack of sufficient control for electric appliances' use is a key limiting factor for developing enough efficiency in electricity consumption in order to minimize electric costs (Munoz, Moreno, Esquivias, Acosta, \& Navarro, 2013). To illustrate the application of control techniques on electric appliances for efficient electric use, data was collected from more than 300,000 detailed single-family house sale records in the Greater Chicago area to investigate the spatial effects neighborhood adoption of energy-efficient heating, 
ventilation, and air conditioning (HVAC) systems (Noonan, Hsieh, \& Matisoff, 2011). The control variables affecting the demand of energy-efficiency, taken as parameters in the spatial error model were neighborhood amenities, distance to central business district (CBD), vacancy rate, population density, and percentage of households that were renters. According to the results from the full sample models, neighborhoods with more newly constructed or recently rehabilitated houses, with larger square footage, and with higher median income and lower population density areas tended to adopt energy-efficient HVACs. Moreover, neighborhoods of houses with larger lot sizes and square footage, with greater wealth, but paying lower tax rates on their properties were more likely to adopt energy-efficient HVACs.

The introduction of the use of energy-saving appliance in buildings is an alternative way to improve energy efficiency. It has been extensively shown that it is possible to have buildings with very low energy use and thus low costs. Significant energy savings as high as $60 \%$ compared with buildings with low-energy efficient appliance use have been found in cold (Wall, 2006), 50\% in tropical (Feng, 2004), $50 \%$ in Mediterranean (Cardinale \& Ruggiero, 2000) climates. Some successful applications of energy-efficient appliance use in buildings are social buildings (Garde et al., 2004, Macias, Mateo, Schuler, \& Mitre, 2006) and office buildings (Pfafferott, Herkel, \& Wambsganß, 2004, Pfafferott et al., 2004), where the energy demand for air conditioning were significantly reduced. The potential development of energy use for future residential heating and air conditioning in the context of climate change was discussed by Isaac and van Vuuren (2009). This research study showed that energy demand for air conditioning is projected to increase rapidly in the 21 st century from close to 300 million megawatts in 2000 , to about 4000 million megawatts in 2050 and more than 10,000 million megawatts in 2100 , mostly driven by increasing income in developing countries. From results obtained from the research, energy demand for heating was forecasted to increase too, mostly due to gradually rising number of people occupying per floor space in buildings.

During the last 30 years, there have been a number of publications, concerning energy saving measures in various types of building. A small part of these publications examine the economic dimension of energy saving measures. Freund (1979) was amongst the first who addressed the costeffectiveness of energy-saving measures in buildings and provided examples for buildings in the United Kingdom. He mentioned that these measures can be regarded as investments, which should be evaluated using some general indicators of cost-effectiveness. He proposed the internal rate of return and produced a ranking by cost-effectiveness of all the measures considered. Kellow (1989) presented Kuwait's approach and experience in the development, introduction and implementation of energy-saving standards in buildings. Although Kuwait is rich in energy resources, a review of the growth in energy consumption revealed the need for energy saving, particularly in the building sector. The Ministry of Electricity and Water of Kuwait responded by introducing guidelines and a set of regulations and mandatory standards for energy saving in buildings. Kellow (1989) presented the potential energy as well as economic savings of their implementation. Other countries that have such guidelines include the United Kingdom, Australia, China, etc. Malaysia has guidelines for non-residential buildings only.
The application of a control strategy on aggregated electric loads was implemented by Callaway \& Hiskens (2011). The process involved automatic generation control and minimizing electricity costs for highly distributed loads to achieve aggregated power control patterns for power system control. Load pattern changes improved system reliability by reducing supply side operating costs. A control strategy for reducing peak-period electricity use loads was presented by Chen et al. (2014). The technique used in the research reduced powersystem overloads risk and revised load-level curve by ensuring the safe operation of distribution lines. A number of studies indicated various factors affecting efficient electricity usage in terms of energy costs reduction, including climatic and environmental issues. Efficiency in electricity consumption was applied to control of Heating Ventilation and Air conditioning systems (HVAC) because of their large energy footprint (Lee, Han, \& Mok, 2009). This involved building a mathematical model of the temperature dynamics of the room, and combining this model with statistical methods allows us to compute the heating load due to occupants and equipment using only a single temperature sensor. A model predictive control (MPC) scheme was proposed for flexible power consumption of refrigeration systems (Shafiei, Stoustrup, \& Rasmussen, 2014), which directly controlled the electrical power consumption of largescale refrigeration systems. A high performance for the power regulation and control for the refrigerator system was obtained by the MPC algorithm. Simulation experiments showed that the proposed MPC algorithm is able to regulate power consumption for the refrigerator with significant magnitude changes of at least $75 \%$ from when control measures were not in place for the refrigerator usage.

The growing demand for electricity consumption makes it imperative to strengthen capabilities in infrastructure and equipment. Focusing on electricity is important because Isaacs, Saville-Smith, Camilleri \& Burrough (2010) indicated that approximately two-thirds of world energy uses are contributed by space heating (34\%). Other contributions are hot water $(29 \%)$, refrigeration (10\%), lighting $(8 \%)$, and other appliances (13\%). Electricity is a very vital source of energy in daily life, especially in buildings. Hence, energy use efficiency can be beneficial to consumers in terms of reduction in energy costs and to the electricity grid in terms of an optimal and efficient allocation of resources to users. The electricity consumption pattern for households in Northern Ireland was investigated by Yohanis, Mondol, Wright, \& Norton (2008). The research generated a 24-hour electricity load profiles for different housing and household attributes using individual housing utility-metering data. A detailed analysis of the effects of applying power-saving measures recorded at 1 minute, 5 minutes, 15 minutes and 30 minutes time intervals was applied on domestic electricity profiles in households (Wright \& Firth, 2007). The study showed electricity load profile varies from house to house.

The rising costs of electricity bills make people think about reducing their power consumption. Lack of information is a major hurdle for people who want to reduce energy consumption in their homes (Weiss, Mattern, Graml, Staake \& Fleisch, 2009). According to the study, receiving electricity bills together with monthly feedbacks is not sufficient for consumer behavior change. In order to adapt their behavior more efficiently, users need to understand how much energy different appliances consume. Such feedbacks should be given to consumers to enable them to adjust their behavior and 
conserve energy. Increasing energy savings for chillers and water pumps by using energy in an efficient manner was proposed by Saidur, Hasanuzzaman, Mahlia, Rahim, \& Mohammed (2011). The research involved a significant reduction in energy consumption for these appliances. Saidur (2009) proposed energy-saving strategies for major appliances by controlling their energy use leading to energy costs reduction. The paper also compared energy use of office building appliances in different countries by measuring their respective energy performances.

A study by Fischer (2008) investigated the use of feedback as a tool for customers to control their household electricity consumption in order to save energy. The research developed an environmental-based energy model to explore environmentally relevant behavior and behavioral change of electricity users in households. The model applied in the research distinguished between two types of actions; habitual behavior or environmentally detrimental habits, and conscious decisions. The model defined habitual behavior as the attitude of electricity users towards such everyday activities as switching on lights when in use and switching off lights when not in use and defines conscious decision as electricity users been fully aware of cost saving measures for their various electric appliances. The effectiveness of the model used in the research was determined by relevant features, which were identified during the research and consisted of frequency of feedbacks from electricity users, duration of time electric appliances were in use and not in use, type of electric appliance in use, and comparisons and combination of various electric appliances in use. The research concurred that a successful long-term feedback can be achieved if there is a close link between specific actions or attitude of electricity users and their effects on energy savings. It also proposed that appliance-specific feedback helped consumers make a conscious choice of appliances based on their duration and modes of use with the ultimate goal of electricity savings. The research further suggested the usefulness of a successful feedback for promoting electricity conservation in households which included feedback based on actual appliances' consumption, appliances-specific consumption, readings given frequently (ideally daily or more times), and readings given over a long period of time. The challenge of reducing energy costs in buildings requires behavioral changes in life styles and energy consumption patterns in people, and the use of more energy efficient production, processing and distribution technologies.

\section{MEASURING DATA FOR HOUSEHOLD APPLIANCES}

There are two main types of devices used for monitoring household electricity consumption; the first focuses on monitoring a building's electricity consumption, and the second allows monitoring at the individual appliance level (Energy Monitor, 2012). Many devices have been developed for measuring whole building electricity consumption. Most of these devices use an inductive sensor design placed in the main power supply of the building through the electricity company supplied meter.

The Wattson energy meter shows how much electricity a building is using in watts, and has a transmitter attached to the consumer's electricity meter (Smart Home Energy, 2015). It displays both numbers and colors to provide feedback to the homeowners about their energy consumption. When the lights glow blue, less electricity than normal is being used; when it glows purple, average electricity is being used, and when it's red, more electricity than usual is being used. This device has LED display which can show electricity use in kilowatts or in different types of currency such as euro, or pound. Additionally, this device has a memory that can record up to four weeks of data and this data can show daily, weekly and monthly consumption with software included for connection to the computer for real-time data reading. The OWL is another device for monitoring the whole house electricity consumption and provides real-time information on the amount of electricity being consumed (Energy Saving and Monitoring in New Zealand, 2015). The LCD screen of this device can display a large amount of information for customers, such as date, time, temperature, power consumption, current consumption and greenhouse gas emissions, which can help to reduce power usage. The user of OWL can set up a power usage limit and when the power goes above this limit, the alarm function in this device will alert the user. This device can store up to 30 days data, which can be uploaded to a computer.

The Belkin Conserve Insight is another measuring device which is connected to the main power outlet of a building. The LCD can display the usage in dollars, watts and also the carbon dioxide emitted by appliances for 45 minutes. The Power Mate was developed to show the running cost for individual appliances based on the behavior of these appliances (Energy Monitor, 2015). Power Mate shows the running cost for the appliance (per hour, per week, per quarter or per year), the greenhouse gas emissions, and the increasing and expected appliance power usage.

\section{MODELING APPLIANCE USAGE}

Although there are a lot of research published about appliance consumption and usage patterns, few match the specific goals of this study, which include understanding the energy demands and usage patterns of household appliances, with the intention of developing statistical models for use in a largescale simulation. In order for households to increase the awareness of the pattern of their electricity consumption, it is expedient to break down their whole house energy consumption (Ruzzelli, Nicolas, Schoofs \& O'Hare, 2010). World Energy Outlook 2013 in its presentation identified developing appropriate models for planning and management in the energy market as a means of achieving efficient electricity consumption in electrical appliance use. The study indicated that the introduction of new tools in analyzing energy models would minimize economic losses, since this has become a tool for optimizing energy resources and accurately allocating energy resources, thus improving efficiency in electric appliance use. The research concluded that more energy savings can be achieved if future electricity to be consumed by individual appliances can be accurately forecasted. Forecasting electricity consumption in buildings has been studied by several researchers. The forecasted values obtained from these studies ranged from an hour, over a week, to a year. In predicting consumption values, temperature, humidity along with past consumption is considered for demand projection (Nogales et. al. 2002).

Consequently, a review of techniques for modeling electricity consumption is undertaken.

\subsection{Regression and Time series models}

A combination of Holt-Winters method and seasonal regression model was used to predict electricity consumption 
(Lepojevi \& An, 2011). However, the success of applying forecasting method in the study depended on identifying the proper choice of method in order to provide high-quality and reliable forecasts. The impact of economic and demographic variables on annual electricity consumption in New Zealand was investigated by Mohamed \& Bodger (2005). The study utilized gross domestic product, average price of electricity and population of New Zealand. Models were developed using multiple linear regression analysis. The models performed effectively well in the statistical tests conducted, meaning that the variables considered for the study were significant in forecasting electricity consumption. A drawback to this approach is that the accuracy of the forecasts made by these models depended strongly on the accuracy of forecasts made for the independent variables. Sughnathi (2012) presented a comprehensive review of techniques for predicting energy demand. This included traditional methods such as time series, regression, econometric, auto regressive integrated moving average method for solving demand side management problems. The paper proposed the adoption of the various energy demand techniques to accurately predict energy consumption. The techniques presented are extensively used in demand side management, which is required for proper allocation of available energy resources.

Lam, Wan \& Liu (2010) attempted to develop simple regression models for office buildings because of the growing concern about energy use caused by rapid building development programmes and improvements in the living conditions of households. The database used for multiple regression analysis in the study consisted of simulated annual building energy use for different households. The study concluded that a strong relationship exists between annual energy usage and building design parameters, with small standard errors. Bacher, Madsen, Nielsen \& Perers (2013) presented an adaptive linear, forward selecting time-series modeling technique to forecast load for space heating in buildings. It utilized ambient temperature, global radiation and wind speed as inputs to its model. The presented heat load forecasts in the study were used as input for the optimization of heat supply to buildings in smart grid applications. The use of regression models using economic and demographic variables to develop a long-term consumption forecasting model was proposed by Bianco, Manca \& Nardini (2009). The variables considered in the research were historical electricity consumption, gross domestic product (GDP), gross domestic product per capita (GDP per capita) and population. Braun, Altan \& Beck (2014) described the energy consumption of a supermarket in Northern England by means of a multiple regression analysis based on its gas and electricity data. As part of the study, the research utilized prevalent weather conditions such as temperature and humidity.

A research to undertake a broad examination of monthly residential electricity demand was carried out using Excel and step-wise regression (Kros, 2011). It investigated the impact of the various seasons on electricity demand. Prediction models for electricity demand and their various statistical parameters were assessed. The paper proposed that any method with the smallest percentage error could be selected to effectively develop forecasts for residential electricity usage. The adequacy of Box Jenkins approach to time series modeling was discussed by Asamoah et al. (2012). The Box Jenkins method used in this study was able to estimate energy supply model in order to meet the demand requirements of customers. Results obtained from the study indicated that the method is adequate for time-series data modeling. A study to estimate the demand for electricity in the household sector was carried out by Athukorala \& Wilson (2010). The study investigated the short-run dynamics and long-run equilibrium relationship between household electricity consumption and factors influencing it. These factors include household income, price of electricity, price of kerosene oil and price of liquefied petroleum gas. The estimation process of the model involves examining the time series properties of the data series for the Augmented Dickey-Fuller (ADF) model. The model is given as:

$\Delta \mathrm{Y}_{\mathrm{t}}=\beta_{1}+\beta_{2} \mathrm{t}+\alpha \mathrm{Y}_{\mathrm{t}-1}+\alpha_{\mathrm{i}} \Delta_{\mathrm{t}-\mathrm{i}}+\mathrm{U}_{\mathrm{t}}$

where

$\Delta \mathrm{Y}_{\mathrm{t}}=$ first difference of $\mathrm{Y}$ variable

$\Delta_{\mathrm{t}-1}=$ one period lag of $\mathrm{Y}$ variable

$\mathrm{U}_{\mathrm{t}}=$ stochastic error term

$\mathrm{i}=1, \ldots, \mathrm{n}$

\subsection{Markov models}

A paper by Widén \& Wäckelgård (2010) presented a modeling framework for the generation of high-resolution series of a building's energy plans. The model generated both synthetic activity sequences of individual household members, including occupancy states, and domestic electricity demand based on these plans. The activity-generating model based on non-homogeneous Markov chains were converted to an extensive empirical time-use data set creating a realistic spread of activities over time, down to a 1-min resolution. The research developed a Markov-chain model for generation of synthetic occupancy patterns in households comprising of three states; 'absent', 'present and active', and 'present and inactive'. The occupancy mode included a number of electricity-dependent activities in the active. In a Markovchain model, it is assumed that a person in a household performs individual activities at each discrete time step $\mathrm{k}=1, \ldots \mathrm{N}_{\mathrm{k}}$. When time proceeds from $\mathrm{k}$ to $\mathrm{k}+1$ there is a transition matrix $p_{i j}(k)$ of going from activity state $i$ to $j$. This includes the probability $p_{i i}(k)$ of staying in state $i$. For each time step, a random uniform number is generated and compared to the transition probabilities to determine when transition is takes place. In the study, transition probabilities for a series of data for $\mathrm{N}$ persons showing activities taking place at every time step was given for time steps $\mathrm{k}=$ $1,2, \ldots, \mathrm{N}_{\mathrm{k}}$. All $\mathrm{N}$ transitions between time steps $\mathrm{k}$ and $\mathrm{k}+\mathrm{p}$ were examined and the total number $n_{i j}(k)$ of transition between states $i$ and $j$ were determined from the series. The total number of changes from state $\mathrm{i}$ is then $\mathrm{n}_{\mathrm{i}}(\mathrm{k})=$ $\sum_{j=1}^{N} n_{i j}(k)$, and the transition probability estimate is:

$\mathrm{p}_{\mathrm{ij}}(\mathrm{k})=\frac{\mathrm{n}_{\mathrm{ij}}(\mathrm{k})}{\mathrm{n}_{\mathrm{i}}(\mathrm{k})}$

Richardson, Thomson, Infield \& Clifford (2010) presented a model based upon a combination of patterns of active occupancy (i.e. when people are at home and awake). The domestic electricity demand model developed in the study mapped occupant activity to appliance use and stochastically created synthetic demand data with a 1-min time resolution. The model incorporated appliance use as the basic building block, where "appliance" refers to any individual domestic electricity load, such as a television, washing machine or vacuum cleaner. The appliances used in the model were 
configured using statistical variables describing their mean total annual energy demand and associated power use characteristics, including steady-state consumption or typical use cycles as appropriate. Each appliance in the model had two states: either on or off.

\subsection{Artificial Neural Network}

A number of studies discussed industrial and household energy consumption modeling using artificial neural network (ANN). Artificial neural network was described in Damak (2011) as a hidden-layer feedforward network tool and the most widely used technique for time-series modeling and forecasting. The paper described that the technique is based on pattern recognition, and able to forecast for non-linear models. The back-propagation concept was used to predict residential construction demand in Singapore (Goh, 1998). Neural networks are similar to the least square estimation technique and can be viewed as an alternative statistical approach to solving least squares problems (Chen \& Canizares, 2001). The paper presented an artificial neural network-based short-term load forecasting technique for predicting load in the electricity market. The ANN technique utilized a combination of the three layer feed-forward neural network and a back-propagation training technique. Kalogirou (2000) presented various applications of neural networks using the multiple hidden-layer architecture. This includes modeling and design of a solar steam generating plant and the estimation of heating loads of buildings.

A study by Farinaccio \& Zmeureany (1999) applied neural networks to the disaggregation of whole house energy consumption. The study used a monitor placed in the household power breaker to monitor the whole house and recorded the data every 16 seconds. The research was able to identify and measure electricity consumption for individual appliances. Akole \& Bongulwar (2011) proposed the use of a multi-layer feed forward (FF) artificial neural network trained with back propagation (BP) algorithm to predict half hourly load and price estimates by using historical weather data , load consumption, price and calendar data. Zhang et al. (2010) described the ANN model as a network of three layers of simple connected links; it includes input layer, hidden layer, and output layer. The function of the network is defined as:

$Y_{j}=f\left(\sum_{i} w_{i j} X_{i j}\right)$

where $Y_{j}$ is the output of node $j, f($.$) is the transfer function,$ $\mathrm{w}_{\mathrm{ij}}$ the connection weight between node $\mathrm{j}$ and node $\mathrm{i}$ in the lower layer and $\mathrm{X}_{\mathrm{ij}}$ is the input signal from node $\mathrm{i}$ in the lower layer to node $\mathrm{j}$.

\subsection{Kalman filter Adaptation models}

The issue of obtaining reliable forecasting methods for electricity consumption has been widely discussed by past research works. This is due to the increased demand for electricity and as a result, the development of efficient pricing models. Several techniques have been used in past research for predicting electricity consumption. The Kalman filter The strengths and weaknesses of the issues under study are examined to determine their impact on efficient energy use. adaptation algorithm was adopted for use in this thesis. The Kalman filter is an algorithm that estimates the state of a system from measured data. It was primarily developed by the Hungarian engineer Rudolf Kalman, for whom the filter is named (Subbaram, 2002). Existing research carried out on applying Kalman filter algorithm for predictions shows it has been applied to solving numerical problems (Eldanfour, 2012). The Kalman filters algorithm is widely applied in estimation theory, guidance and navigation systems, econometrics, and signal processing. The technique is a probabilistic approach for estimating an unknown probability density function recursively over time using incoming measurements and developing a mathematical process model from input data. The Kalman filter adaptation algorithm is an optimal estimator, i.e., it infers parameters of interest from indirect, inaccurate and uncertain observations. It is recursive so that new measurements can be processed as they arrived.

A Kalman filter adaptation algorithm was adapted to handle noisy data and non-linear problems at high speed (Madbouly, Abdalla, \& Banby, 2009). The paper mentioned that the technique has been used in diverse applications in control, forecasting, medicine, power systems, robotics, biomedical imaging and signal processing. Elmusrati \& Koivo (2002) introduced a combined algorithm of power control problem and smart antenna based on Kalman filter method. Kalman filter algorithm was applied to the problem to estimate the optimum transmitted power as well as the optimum weights of the smart antenna. The simulation results from the study indicated that the algorithm performed well with respect to convergence speed and robustness of the model. Adaptive Kalman filter method was used for global positioning system (GPS) data filtering (Kluga \& Kluga, 2011). The study described estimates obtained from Kalman filter modelling of dynamic data processing of GPS information. Pavković, Deur \& Kolmanovsky (2009) presented estimation design procedures for automotive power train systems based on adaptive Kalman filter method. The Kalman filter adaptation is based on a simple and robust algorithm that detects sudden changes in factors affecting power train system use.

\section{SUMMARY AND CONCLUSION}

In summary, the above studies are relevant to this study in terms developing load profiles, predicting electricity consumption, and determination of electricity costs for appliance usage in the building. They provide a background about empirical research of achieving efficiency in the energy sector. The important attributes of the three major issues considered in this thesis affecting the efficient usage of appliances in buildings are listed in Table 1. These are modeling consumption of appliance usage; efficiency in electric appliance use; and measuring data for household appliances. These issues are investigated, leading to the development of load profiles and end-uses which bring about efficient power consumption for these appliances. 
Table1 Positive and negative attributes of approaches to power consumption techniques in households

\begin{tabular}{|c|c|c|}
\hline Attributes & Positive attributes & Negative attributes \\
\hline \multirow[t]{12}{*}{ Modeling consumption of appliance usage } & $\begin{array}{c}\text { Determination of power consumption at appliance } \\
\text { level based on simulation }\end{array}$ & Reliant on historical data \\
\hline & Enables application of power-saving measures & Model only supports a two-way process \\
\hline & Impact on consumption based on occupancy & Investigates household profiles during peak periods \\
\hline & $\begin{array}{c}\text { Number and activities of occupants in a household are } \\
\text { known }\end{array}$ & $\begin{array}{l}\text { Does not differentiate between active and inactive } \\
\text { occupancy or location }\end{array}$ \\
\hline & Presents electricity demand based on occupancy state & $\begin{array}{c}\text { No explicit description of consumption at appliance } \\
\text { level }\end{array}$ \\
\hline & Simple input data & $\begin{array}{l}\text { Future electricity to be consumed by individual } \\
\text { appliances not addressed }\end{array}$ \\
\hline & Possible to adjust model to more specific cases & Predication tools affected by size of data \\
\hline & $\begin{array}{c}\text { Investigates effects of load profiles of different } \\
\text { appliances on electricity use }\end{array}$ & $\begin{array}{l}\text { Need to choose the most appropriate predictive } \\
\text { technique }\end{array}$ \\
\hline & $\begin{array}{l}\text { Investigates multiple variables affecting household } \\
\text { consumption profile }\end{array}$ & \\
\hline & Discusses trends & \\
\hline & Models new technology & \\
\hline & Encompasses trends & \\
\hline \multirow[t]{6}{*}{ Efficiency in electric appliance use } & Inclusion of economic benefits & $\begin{array}{l}\text { Does not consider contribution of individual } \\
\text { appliances to energy savings }\end{array}$ \\
\hline & Discusses application of power-saving measures & $\begin{array}{c}\text { Does not specify power requirements for both sellers } \\
\text { and consumers }\end{array}$ \\
\hline & Introduces automated technology for control & Lack of sufficient control for electric appliances' use \\
\hline & Reduces/shifts the peak in loads & \\
\hline & Profile shows when appliances are been used or not & \\
\hline & $\begin{array}{l}\text { Determination of energy use behaviour based on } \\
\text { simulation }\end{array}$ & \\
\hline \multirow[t]{5}{*}{ Measuring data for household appliances } & Measures individual household appliances & $\begin{array}{c}\text { Model under-represents seasonal variation of } \\
\text { electricity demand }\end{array}$ \\
\hline & Determines whether appliance is active or not & Does not cover a typical household \\
\hline & Incorporates daily activity profile & $\begin{array}{l}\text { Small and large transitions in time are under- } \\
\text { represented in the model }\end{array}$ \\
\hline & Utilizes real-time data & Model does not represent those that are inactive \\
\hline & $\begin{array}{c}\text { Determination of one-minute electricity demand based } \\
\text { on simulation }\end{array}$ & \\
\hline
\end{tabular}

The application of power-saving measures on appliance usage will play an increasingly important role in the efficient usage of appliances in buildings; so that work on modeling power consumption behavior is very necessary. Obtaining power consumption models is the premise and basis of predicting power consumption pattern for individual household appliances, and also determining energy costs incurred in appliance usage. The challenges in past research are as follows:

1. There is a need to simulate household consumption patterns for electric devices in order to model the effect of applying power-saving measures on appliance usage.

2. The study of simulating trends for individual appliances.

3. The study of the impact of small appliances on efficient electricity usage.
4. The study of the extent to which power-saving appliance usage affect energy savings.

5. There is the need to study the contribution of individual appliances to energy savings.

6. The study of the scope and nature of change in energy use behavior. Identifying activity profiles for off-peak periods, not only during peaks.

7. There is the need to identify an appropriate predictive technique, for both small and large scale data.

Many control of appliance usage problems, such as simulation of power consumption in buildings are related to energy use behavior and interventions in energy use practices. Considering previous reviews on simulation of power consumption for electric appliances (e.g. Zhou, Yang, \& Shen, 2013), this section reveals similarities and differences, such as the pattern of consumption for appliances in buildings. 
The previous research carried out has already pointed out issues for improvement. Taken together, these reviewed studies have added to our understanding of how to model power consumption for appliances using the techniques mentioned in this study.

In terms of improving efficiency of appliance usage in buildings, it is important to identify behaviors that have a relatively large energy saving potential. By keeping efficiency in use of electric appliances in mind, researchers can focus on consumer behavior that significantly influences appliance efficiency use qualities. Most studies reveal only the extent of applying power-saving measures on appliances, without providing insight into the impact of individual appliances on total consumption. In other words, the effectiveness of the strategy on total consumption and their contribution to energy savings should be examined simultaneously. The development of load profiles for appliance usage and their energy-savings from the application of power-saving measures may increase the understanding of achieving efficiency in the electricity network. The results obtained in this study may help in improving efficient use of appliances.

\section{REFERENCES}

[1] Akole, M. Bongulwar, B. T. 2011. Predictive model of load and price for restructured power system using neural network. International Conference on Energy, Automation, and Signal (ICEAS), 1-6.

[2] Asamoah, D., Annan, J., \& Arthur, Y. D. 2012. Time Series Analysis of Electricity Meter Supply in Ghana, 3(19), 16-22.

[3] Athukorala, P. P. . W., \& Wilson, C. 2010. Estimating short and long-term residential demand for electricity: New evidence from Sri Lanka. Energy Economics, 32, S34-S40. doi:10.1016/j.eneco.2009.08.005

[4] Auffhammer, M., \& Aroonruengsawat, A. 2012. Impacts of climate change on san francisco bay area residential electricity consumption: evidence from billing data. California Energy Commission. Retrieved from www.energy.ca.gov/2012publications

[5] Bacher, P., Madsen, H., Nielsen, H. A., \& Perers, B. 2013. Short-term heat load forecasting for single family houses. Industrial Electronics Society, 5741 - 5746.

[6] Bianco, V., Manca, O., \& Nardini, S. 2009. Electricity consumption forecasting in Italy using linear regression models. Energy, 34(9), 1413-1421. doi:10.1016/j.energy.2009.06.034

[7] Braun, M. R., Altan, H., \& Beck, S. B. M. 2014. Using regression analysis to predict the future energy consumption of a supermarket in the UK. Applied Energy, 130, 305-313. doi:10.1016/j.apenergy.2014.05.062

[8] Callaway, D. S., \& Hiskens, I. a. 2011. Achieving Controllability of Electric Loads. Proceedings of the IEEE, 99(1), 184-199. doi:10.1109/JPROC.2010.2081652

[9] Cardinale, N., \& Ruggiero, F. 2000. Energetic aspects of bioclimatic buildings in the Mediterranean area: A comparison between two different computation methods. Energy and Buildings, 31(1), 55-63. doi:10.1016/S03787788(99)00005-5
[10] Chen, L., Xu, X., Yao, L., \& Xu, Q. 2014. Study of a Distribution Line Overload Control Strategy Considering the Demand Response. Electric Power Components and Systems, 42(9), doi:10.1080/15325008.2014.903545

[11] Chen, C. Canizares, A. S. 2001. ANN-Based Short-Term Load Forecasting in Electricity Markets. Proceedings of the IEEE Power Engineering Society Transmission and Distribution Conference, 411-415.

[12] Damak, S. K. 2011. Applications of two identification methods for an electric distribution system. J. Automation \& Systems Engineering, 4(5-4), 176-184.

[13] Eldanfour, H. 2012. Modified Newton's methods with fifth or sixth-order convergence. Proceedings of the International Conference in Mathematics, 149-152.

[14] Elmusrati, M., \& Koivo, H. 2002. Joining power control and smart antenna using kalman algorithm. Proc. the XXVIITH General Assembly of URSI, (1), 2-5.

[15] Energy Saving and Monitoring in New Zealand. 2015. www.energymonitor.org.nz/. Retrieved from www.energymonitor.org.nz/

[16] Farinaccio, L., \& Zmeureany, R. 1999. Using a pattern recognition approach to disaggregate the toal electrical consumption in a house into the major end-uses. Energy and Buildings, 245-259.

[17] Fischer, C. 2008. Feedback on household electricity consumption: a tool for saving energy? Energy Efficiency, 1(1), 79-104. doi:10.1007/s12053-008-90097

[18] Fontana, L., Atella, V., \& Kammen, D. M. 2013. Energy efficiency as a unifying principle for human, environmental, and global health. F1000Research, 2, 101. doi:10.12688/f1000research.2-101.v1

[19] Freund P. 1979. The cost-effectiveness of some measures for energy conservation in buildings in the UK. Build. Serv. \& Environ. Eng., 6, 69-79.

[20] Garde, F., Adelard, L., Boyer, H., \& Rat, C. 2004. Implementation and experimental survey of passive design specifications used in new low-cost housing under tropical climates. Energy and Buildings, 36(4), 353-366. doi:10.1016/j.enbuild.2004.01.045

[21] Goh, B. 1998. Forecasting residential construction demand in Singapore: a comparative study of the accuracy of time series, regression and artificial neural network techniques. Engineering, Construction and Architectural Management, 5(3), 261-275.

[22] International Energy Agency. 2013. Key World Energy Statistics. Retrieved from http://www.iea.org/publications/freepublications/publicat ion/KeyWorld2013.pdf

[23] Isaac, M., \& van Vuuren, D. P. 2009. Modeling global residential sector energy demand for heating and air conditioning in the context of climate change. Energy Policy, 37(2), 507-521. doi:10.1016/j.enpol.2008.09.051

[24] Isaacs, N. and Saville-Smith, K. and Camilleri, M. and Burrough, L. 2010. Energy in New Zealand Houses: 
comfort, physics and consumption. Building Research and Information, 38, 470-480.

[25] Kalogirou, S. a. 2000. Applications of artificial neuralnetworks for energy systems. Applied Energy, 67, 1735. doi:10.1016/S0306-2619(00)00005-2

[26] Kellow. 1989. Kuwait's approach to mandatory energyconservation standards for buildings. Energy, 14(8), 491-502.

[27] Kluga, A., \& Kluga, J. 2011. Dynamic Data Processing with Kalman Filter, 5(5), 5-8.

[28] Kros, J. F. 2011. Seasonal Influences on Electricity Demand in the Mid-Atlantic Region. Advances in Business and Management Forecasting, (8), 13 - 29.

[29] Lam, K. Wan, D. Liu, C., T. 2010. Multiple Regression Models for Energy Use in Air-conditioned Office Buildings in Different Climates. Energy Conversion and Management, 2692-2697.

[30] Lee, H. Kim, G. Park, M. K. 2012. Energy Consumption Scheduler for Demand Response Systems in the Smart Grid *, 969, 955-969.

[31] Lee, J., Han, S., \& Mok, A. K. 2009. Design of a Reliable Communication System for Grid-Style Traffic Control Networks. IEEE Real -Time \& Embedded Technology and Applications Symposium, 133-142.

[32] Lepojevi, V., \& An, M. 2011. Forecasting electricity consumption by using holt-winters and seasonal regression models, 8(179066), 421-431.

[33] Macias, M., Mateo, a., Schuler, M., \& Mitre, E. M. 2006. Application of night cooling concept to social housing design in dry hot climate. Energy and Buildings, 38(9), 1104-1110. doi:10.1016/j.enbuild.2005.12.006

[34] Madbouly, E. E. El, Abdalla, a. E., \& Banby, G. M. El. 2009. Fuzzy adaptive Kalman filter for multi-sensor system. 2009 International Conference on Networking and Media Convergence, 1-9. doi:10.1109/ICNM.2009.4907206

[35] Mohamed, Z., \& Bodger, P. 2005. Forecasting electricity consumption in New Zealand using economic and demographic variables. Energy, 30(10), 1833-1843. doi:10.1016/j.energy.2004.08.012

[36] Monitor, E. 2015. Appliance monitoring.

[37] Munoz, C. M., Moreno, D., Esquivias, P., Acosta, I., \& Navarro, J. 2013. Energy and Cost savings by Using Lighting Controls in offices. International Energy Agency, 1-7. Retrieved from http://www.ilc2013.com/paper/Session 2b C Munoz Energy and cost savings by using lighting controls in offices.pdf

[38] Naidu Subbaram. 2002. Optimal Control Systems, 131.

[39] Nogales et. al. 2002. Forecasting next-day electricity prices by time series models. IEEE Transactions on Power Systems, 17, 342-348.

[40] Noonan, D. S., Hsieh, L.-H. C., \& Matisoff, D. 2011. Spatial Effects in Energy-Efficient Residential HVAC Technology Adoption. Environment and Behavior, 45(4), 476-503. doi:10.1177/0013916511421664
[41] Pavković, Deur, Kolmanovsky, H. 2009. Application of Adaptive Kalman Filter for Estimation of Power Train Variables. SAE Int. Journal of Passenger Cars, 1(1), 480-491.

[42] Pfafferott, J., Herkel, S., \& Wambsganß, M. 2004. Design, monitoring and evaluation of a low energy office building with passive cooling by night ventilation. Energy and Buildings, 36(5), 455-465. doi:10.1016/j.enbuild.2004.01.041

[43] Richardson, I., Thomson, M., Infield, D., \& Clifford, C. 2010. Domestic electricity use: A high-resolution energy demand model. Energy and Buildings, 42(10), 18781887. doi:10.1016/j.enbuild.2010.05.023

[44] Ruzzelli, a. G., Nicolas, C., Schoofs, A., \& O'Hare, G. M. P. 2010. Real-time recognition and profiling of appliances through a single electricity sensor. SECON 2010 - 2010 7th Annual IEEE Communications Society Conference on Sensor, Mesh and Ad Hoc Communications and Networks, 1-9. doi:10.1109/SECON.2010.5508244

[45] Saidur, R. 2009. Energy consumption, energy savings, and emission analysis in Malaysian office buildings. Energy Policy, 37(10), 4104-4113. doi:10.1016/j.enpol.2009.04.052

[46] Saidur, R., Hasanuzzaman, M., Mahlia, T. M. I., Rahim, N. \& Mohammed, H. 2011. Chillers energy consumption, energy savings and emission analysis in an institutional buildings. Energy, 36(8), 5233-5238. doi:10.1016/j.energy.2011.06.027

[47] Shafiei, S. E., Stoustrup, J., \& Rasmussen, H. 2014. Model Predictive Control for Flexible Power Consumption of Large-Scale Refrigeration Systems. American Control Conference.

[48] Smart Energy Home. 2015. Wattson energy monitoring.

[49] Sughnathi, S. A. 2012. Energy models for demand forecasting - A Review. Renewable and Sustainable Energy Reviews, 16, 1223-1240.

[50] Tom, K. 2010. Energy efficiency: A compelling global resource. Retrieved from https://www.mckinsey.com/ /.../A_Compelling_Global_ Resource.ashx

[51] Wall, M. 2006. Energy-efficient terrace houses in Sweden: Simulations and measurements. Energy and $\begin{array}{ll}\text { Buildings, } & 38(6),\end{array}$ doi:10.1016/j.enbuild.2005.10.005

[52] Weiss, M., Mattern, F., Graml, T., Staake, T., \& Fleisch, E. 2009. Handy feedback: Connecting smart meters with mobile phones. Interface, 1-4. doi:10.1145/1658550.1658565

[53] Widén, J., \& Wäckelgård, E. 2010. A high-resolution stochastic model of domestic activity patterns and electricity demand. Applied Energy, 87(6), 1880-1892. doi:10.1016/j.apenergy.2009.11.006

[54] World Energy Outlook 2013. 2013. International Energy Agency. doi:10.1787/weo-2013-en

[55] Wright, A., \& Firth, S. 2007. The nature of domestic electricity-loads and effects of time averaging on 
statistics and on-site generation calculations. Applied Energy,84(4),389403.doi:10.1016/j.apenergy.2006.09.00 8

[56] Yohanis, Y. G., Mondol, J. D., Wright, A., \& Norton, B. 2008. Real-life energy use in the UK: How occupancy and dwelling characteristics affect domestic electricity use. Energy and Buildings, 40, 1053-1059. doi:10.1016/j.enbuild.2007.09.001
[57] Zhang, G. P., Areekul, P., Member, S., Senjyu, T., Member, S., \& Toyama, H. 2010. A Hybrid ARIMA and Neural Network Model for Short-Term Price Forecasting in Deregulated Market. IEEE Transactions on Power Systems, 25(1), 524-530.

[58] Zhou, K., Yang, S., \& Shen, C. 2013. A review of electric load classification in smart grid environment. Renewable and Sustainable Energy Reviews, 24, 103110. doi:10.1016/j.rser.2013.03.023 